\title{
Editorial
}

\section{The road ahead}

Asian Business \& Management (2014) 13, 1-4. doi:10.1057/abm.2013.23

This issue marks the beginning of the third year of my editorship of Asian Business \& Management $(A B M)$. Thanks to the solid foundations laid by my predecessor and founding editor, Harukiyo Hasegawa, and the continued support of the Palgrave team, the journal has continued to thrive. One piece of evidence of this is the general upward trend of our Social Science Citation Index 3-Year Impact Factor, which reached a historical highpoint of 1.333 in 2012 . While these metrics are bound to fluctuate, the overall trajectory has been highly encouraging.

\section{Editorial Structure: How Are Decisions Made?}

To ensure that this upward trend is sustainable into the future, we have been transitioning to a new editorial structure. Submissions to $A B M$ were originally vetted by a pre-review board composed of about half a dozen Senior Editors. Articles passing this pre-review stage would then be sent out for review under the auspices of the General Editor.

While this process has served the journal well, it has had two main drawbacks. One is that the pre-review process has tended to add considerably to the turnaround time of the journal, which has been a disadvantage to both authors and journal. More importantly, having the General Editor as the sole decision maker means that the future of the journal is highly dependent on the ability and availability of a single person. As we all know from the management literature, this can pose certain challenges.

We are consequently moving towards a distributed decision-making structure in which Associate Editors will guide papers through the review process within their specific areas of expertise, and make the final decisions on these pieces. Submissions will still be initially assessed in terms of suitability for the journal and whether more needs to be done ahead of review, but this will be done by the General Editor and respective Associate Editor rather than a pre-review board. The overall impact should be a higher cumulative level of expertise in editorial decision making in $A B M$, more pluralism in papers we publish, and a reduction in turnaround time of several weeks for papers that go out for review. 


\title{
Positioning of the Journal: What Kinds of Papers Are Publishable in $A B M ?$
}

On the other hand, there is no change in the kinds of article that $A B M$ seeks to publish. In my first Editorial, published in $A B M 11.1$ (Witt, 2012; www.palgravejournals.com/abm/journal/v11/n1/full/abm201123a.html), I wrote:

\begin{abstract}
$A B M$ is, as the name suggests, a journal on business and management in Asia. It views itself as an academic general management and business journal, that is, we are in principle open to all disciplines and fields of research on management and business - subject, of course, to the condition that submissions must be related to Asia. We especially encourage papers that draw on one of the various streams of the business systems literature, broadly conceived, to generate new insights into the societal embeddedness of firms in Asia and the consequences of such embeddedness on managerial and business processes, structures and outcomes.
\end{abstract}

This and other thoughts on the $A B M$ perspective are set out in this editorial, which remains equally valid today. When considering submitting an article, this editorial may help prospective authors to check that their papers are aligned with our positioning.

After 2 years at the helm, I look back on several hundred submissions, relatively few of which were found appropriate for $A B M$, and here I would like to make some suggestions that may be helpful for future contributors, especially regarding the construction of a submitted paper.

Surprisingly, many papers say little or nothing about business or management in Asia. There are the occasional clear misfits, such as papers on Italy or Brazil, which by any stretch of the imagination are about non-Asian locations. But more generally, some papers, while using Asian samples, fall down on a lack of new insights into business or management in Asia, such as by simply representing general universal theory in a different context. A typical example might argue that employees who are more content in their jobs are likely to remain with the same employers longer; in our view, it would be surprising to find any national context where, ceteris paribus, this would not be the case, so there is no real value added. However, developing the topic into questions such as 'What determines contentment?' would carry the argument into areas of local cultural and institutional context, and that is where new insights about business and management in Asia could be generated.

By extension, the cultural and institutional context should be brought into the discussion. There is already a broad literature on cross-cultural management. By contrast, the literature on institutional variations is considerably younger. Especially significant in this area are the Oxford Handbook of Asian Business Systems (Witt and Redding, 2014) and related pieces in the varieties of capitalism and business systems literatures (for example, Whitley, 1992, 1999; Orrù et al, 1997; Redding and Witt, 
2007; Witt and Redding, 2013). Ideally, the differences portrayed in these and/or the cross-cultural works would be taken into account already in the design stages of new research. However, at a minimum, successful papers need to generate new insights into what is Asian about the phenomenon observed.

In this context, it is crucial for papers to have a clear contribution to theory. Sometimes, this point is missed altogether, but more often, while the implications are present, they are not spelt out. This places both author and reader at a disadvantage. The question to ask here is: Why should anybody later on cite your paper? Framed this way, it becomes clear that a claim of significance along the lines of 'this is the first paper to study theory $\mathrm{X}$ in Laos' does not take a paper very far.

It is also useful to bear in mind that $A B M$ 's primary audience is academics, rather than practitioners or governments. This means we foremost value contributions to theory; while managerial implications are acceptable, they are ultimately optional, and papers without a clear theoretical contribution will usually not make it through the review process. Conversely, papers with a clear theoretical contribution but no managerial implications are much more likely to be accepted.

Important in this context is, in $A B M$ as elsewhere, the quality of craftsmanship. Although our standards differ from those of other leading journals in the field, in line with what we consider more appropriate for emerging-market data, we do expect authors to do what is sensibly possible. For instance, many empirical analyses do not properly control for alternative explanations. Even among those that do, it is rare to see proper handling of IID violations in regression analyses. These violations are problematic because in many cases, they result in artificially small standard errors and thus artificially high statistical significance. Papers need to be much more conscientious in using cluster-corrected standard errors or hierarchical linear models where clusters are present in the data. Robustness checks using different regression methodology should also be part of the standard repertoire.

I hope these remarks may be of help to prospective authors, in establishing and clarifying some aspects of how to approach and pitch a paper within the $A B M$ remit. If you feel your paper fits the bill of pushing forward out theoretical understanding of business and management in the Asian context, we certainly welcome the opportunity to take a look at it, and we look forward to improvements in turnaround time and quality as these criteria work through.

\section{References}

Orrù, M., Biggart, N.W. and Hamilton, G.G. (1997) The Economic Organization of East Asian Capitalism. London: Sage Publications.

Redding, G. and Witt, M.A. (2007) The Future of Chinese Capitalism: Choices and Chances. Oxford, UK: Oxford University Press.

Whitley, R. (1992) Business Systems in East Asia: Firms, Markets and Societies. London: Sage Publications. 
Whitley, R. (1999) Divergent Capitalisms: The Social Structuring and Change of Business Systems. Oxford, UK: Oxford University Press.

Witt, M.A. (2012) Editorial. Asian Business and Management 11(1): 1-4.

Witt, M.A. and Redding, G. (2013) Asian business systems: Institutional comparison, clusters and implications for Varieties of Capitalism and business systems theory. Socio-Economic Review 11(2): 265-300.

Witt, M.A. and Redding, G. (eds.) (2014) The Oxford Handbook of Asian Business Systems. Oxford, UK: Oxford University Press.

Michael A. Witt INSEAD, Singapore 